\title{
Indication-based prescribing prevents wrong-patient medication errors in computerized provider order entry (CPOE)
}

\author{
William Galanter, ${ }^{1}$ Suzanne Falck, ${ }^{1}$ Matthew Burns, ${ }^{1}$ Marci Laragh, ${ }^{1}$ Bruce L Lambert ${ }^{2}$
}

1 Department of Medicine, University of Illinois at Chicago, Chicago, Illinois, USA ${ }^{2}$ Department of Pharmacy Administration, University of Illinois at Chicago, Chicago, Illinois, USA

\section{Correspondence to} Dr William Galanter, Department of Medicine, University of Illinois at Chicago, 840 South Wood, M/C 718, Chicago,

IL 60062, USA;

billg@uic.edu

Received 6 December 2012 Revised 17 January 2013 Accepted 20 January 2013 Published Online First 9 February 2013

To cite: Galanter W Falck S, Burns M, et al. J Am Med Inform Assoc 2013;20:477-481.

\begin{abstract}
Objective To determine whether indication-based computer order entry alerts intercept wrong-patient medication errors.
\end{abstract}

Materials and methods At an academic medical center serving inpatients and outpatients, we developed and implemented a clinical decision support system to prompt clinicians for indications when certain medications were ordered without an appropriately coded indication on the problem list. Among all the alerts that fired, we identified every instance when a medication order was started but not completed and, within a fixed time interval, the same prescriber placed an order for the same medication for a different patient. We closely reviewed each of these instances to determine whether they were likely to have been intercepted errors.

Results Over a 6-year period 127320 alerts fired, which resulted in 32 intercepted wrong-patient errors, an interception rate of 0.25 per 1000 alerts. Neither the location of the prescriber nor the type of prescriber affected the interception rate. No intercepted errors were for patients with the same last name, but in $59 \%$ of the intercepted errors the prescriber had both patients' charts open when the first order was initiated.

Discussion Indication alerts linked to the problem list have previously been shown to improve problem list completion. This analysis demonstrates another benefit, the interception of wrong-patient medication errors.

Conclusions Indication-based alerts yielded a wrong-patient medication error interception rate of 0.25 per 1000 alerts. These alerts could be implemented independently or in combination with other strategies to decrease wrong-patient medication errors.

\section{BACKGROUND AND SIGNIFICANCE}

Use of computerized physician order entry (CPOE) systems for the placement of medication orders is part of the hospital-based and the eligible provider components of the US government's meaningful use incentives. ${ }^{1}$ While CPOE has been shown to decrease medication errors ${ }^{2-4}$ and in some studies mortality, ${ }^{5}$ use of CPOE can also have unintended negative consequences, creating opportunities for or increasing the likelihood of certain types of medication errors. ${ }^{6-9}$

One potential problem with an electronic medical record (EMR) is the risk that a physician will accidentally enter orders in the wrong patient's chart. ${ }^{8-10}$ In spite of all their disadvantages, paper charts afforded prescribers multiple visual cues that served to orient them to whether or not they were ordering for the correct patient, including the thickness of the chart, the handwriting, and the patient's problem list. ${ }^{10}$ Most of these cues are either missing entirely or are less salient in the electronic environment, increasing the opportunity for wrong-chart errors. Use of patient lists may cause 'pick-list' or other user-interface driven errors, ${ }^{11}$ and wrong patient selection may be facilitated by system features that allow clinicians to find charts rapidly, such as the ability to select from a list of recently opened charts, or to have multiple patient charts open simultaneously.

A study by Wilcox and Chen estimated that $0.3-0.5 \%$ of clinical notes were placed in the wrong patient's electronic chart. ${ }^{12} \mathrm{~A}$ recent study by Adelman $e t a l^{13}$ estimated that for about 1 in 1000 medication orders, clinicians realized that they had placed the order on the wrong patient chart and canceled it prior to any medication administration.

As part of a separate project, we previously developed and implemented a set of clinical decision support (CDS) alerts to prompt prescribers to add problems to the problem list when they were prescribing certain medications in the absence of certain documented problems. When analyzing the effectiveness of these alerts, which did in fact improve the completeness and accuracy of problem lists, ${ }^{14}{ }^{15}$ we noticed that a small percentage of the time, prescribers canceled medication orders immediately after receiving an indication alert. We suspected that the indication alerts may have improved the prescribers' situation awareness and made them realize that they were about to order a medication for the wrong patient.

\section{Objective}

Our aim was to determine whether or not indication-based prompts during $\mathrm{CPOE}$ of medications might help clinicians to identify and cancel wrong-patient medication orders, thereby intercepting the errors before orders were completed and medications administered.

\section{MATERIALS AND METHODS}

The University of Illinois Hospital and Health Sciences System (UI-Health) has a 450-bed teaching hospital and a large multi-specialty ambulatory clinic utilizing a commercial EMR (Millennium; Cerner Corporation, Kansas City, Missouri, USA) for problem lists, clinical notes, test results, medication lists, and orders. The EMR is used by all specialties, allowing any clinician to update patient records and problem lists either as free text or using common discrete coded nomenclatures 
(ICD-9 $\mathrm{CM}^{16}$ or SNOMED ${ }^{17}$ ). All medication orders are placed by $\mathrm{CPOE}$ which is associated with a commercially available CDS system (Discern Expert; Cerner Corporation) which has been described previously for this and other types of alerts. ${ }^{14} 151819$

Orders for specified medications (table 1) triggered an alert for the clinician to update the medical record for patients whose electronic problem list did not contain an active problem indicated by that medicine. Depending on the medication, alerts displayed one or more possible problems (figure 1). The clinician could select one or more of the offered problems, choose not to enter a problem at all, or cancel the order. Once selected, problems were added automatically to the patient's problem list in the EMR. Clinicians at UI-Health are familiar with similar types of CDS, so we performed no additional physician training.

All specified medication indications triggered alerts in all locations of the medical center, with the exception of insulin, which triggered alerts only in the ambulatory setting, as insulin is very specific to diabetes for outpatients, but in the hospital is frequently prescribed for non-diabetic patients in order to maintain tight glycemic control.

Alerts triggered from April 2006 through February 2012 were analyzed to identify sequences that met the following criteria: (a) an order was started but not completed for a given patient; and (b) within $10 \mathrm{~min},{ }^{13}$ the same prescriber submitted an order for the same medication for a different patient. An experienced clinician then completed a chart review of each of these identified instances to decide whether the first order attempt was an intercepted wrong-chart error.

Table 1 Alert groups with corresponding medications

\begin{tabular}{|c|c|}
\hline Alert group name & Medications \\
\hline S/P CVA & Aspirin-dipyridamole \\
\hline COPD/asthma & Fluticasone, fluticasone/salmeterol, tiotropium \\
\hline Diabetes mellitus oral & $\begin{array}{l}\text { Rosiglitazone, repaglinide, pioglitazone, nateglinide, } \\
\text { metformin, glimepiride, sulfonylureas, and } \\
\text { combinations of these medications }\end{array}$ \\
\hline Factor VIla & Coagulation factor VIla \\
\hline HTN & $\begin{array}{l}\text { Aliskiren, amiloride, } \beta \text { blockers except } \\
\text { metoprolol-succinate and carvedilol), calcium } \\
\text { channel blockers, clonidine, furosemide, guanfacine, } \\
\text { methyldopa, metolazone, minoxidil, nitroprusside } \\
\text { thiazides, triamterene, and combinations of these } \\
\text { medications }\end{array}$ \\
\hline HTN/CHF & $\begin{array}{l}\text { Carvedilol, hydralazine, isosorbide dinitrate, } \\
\text { metoprolol succinate, spironolactone }\end{array}$ \\
\hline HTN/BPH & $\alpha$ Blockers \\
\hline HTN/CHF/nephropathy & ACE, ARB \\
\hline HIV & $\begin{array}{l}\text { NRTIs, NtARTIs or NtRTIs, NNRTIs, protease } \\
\text { inhibitors }\end{array}$ \\
\hline Hyperlipidemia & $\begin{array}{l}\text { HMG-CoA reductase inhibitors, red yeast rice, } \\
\text { niacin, fibric acids, ezetimibe, cholestyramine }\end{array}$ \\
\hline $\begin{array}{l}\text { Intravenous immune } \\
\text { globulin }\end{array}$ & Intravenous immune globulin (IVIG) \\
\hline Osteoporosis & Bisphosphonates \\
\hline Ambulatory insulin & Insulins \\
\hline Pediatric asthma & Albuterol \\
\hline $\begin{array}{l}\text { Proton pump inhibitors } \\
\text { (PPI) }\end{array}$ & PPI \\
\hline $\begin{array}{l}\text { Selective serotonin } \\
\text { reuptake inhibitors }\end{array}$ & Selective serotonin reuptake inhibitors (SSRI) \\
\hline Hypothyroidism & Levothyroxine; liotrix, thyroid desiccated \\
\hline
\end{tabular}

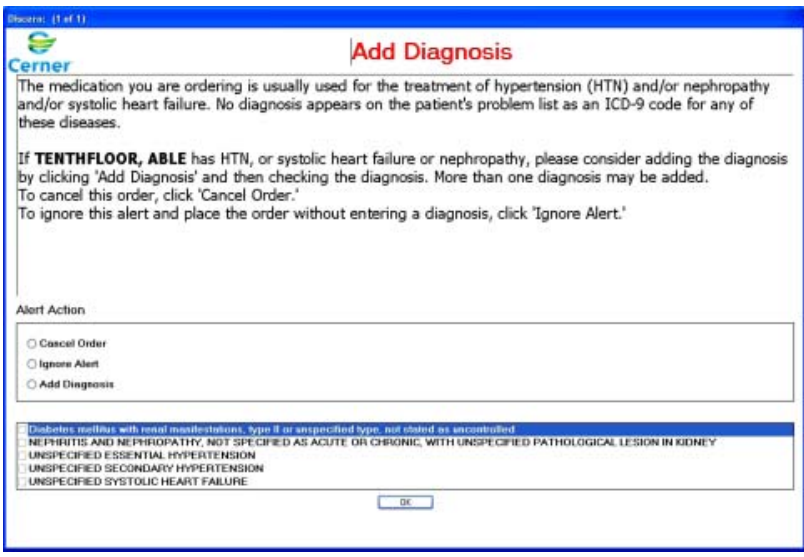

Figure 1 Indication alert for angiotensin converting enzymes (ACE) inhibitors and angiotensin receptor blockers (ARB).

Two criteria were applied during chart review: first, that the patient was not currently being prescribed the medication (this criterion was required due to limitations of automated review and medication lists) and second, that the medication was inconsistent with the clinical condition(s) of the patient and a review of clinical notes. A second reviewer then confirmed all possible intercepted errors by the first chart reviewer.

Intercepted errors were expressed as the number of intercepted errors per 1000 alerts. For each of these proportions measured, the SE of the proportion was determined. Some proportions were compared using $\chi^{2}$ tests with significance defined with a $\mathrm{p} \leq 0.05$.

This study was approved by the University of Illinois Institutional Review Board. A waiver of consent for both the patient and clinician subjects was obtained.

\section{RESULTS}

Over the nearly 6-year period, from April 2006 to February 2012, the system fired 127320 alerts on 79304 encounters with 54608 unique patients. The distribution by location was $42 \%$ inpatient, $38 \%$ outpatient, $14 \%$ in the emergency department (ED), and $6 \%$ undefined. Housestaff received $77 \%$ of the alerts, attending physicians $18 \%$, and $5 \%$ others (registered nurses, pharmacists, advanced practice nurses, nurse practitioners, medical students, etc). Of these alerts, $3462(2.72 \%)$ were not associated with an order for the medication during the encounter. Chart review was performed on 822 charts involving an order within 2 min prior to and $20 \mathrm{~min}$ after the alert due to some slight differences in the alert and order times in our reports.

Chart review identified 32 intercepted wrong chart errors from the 127320 alerts (table 2). None of these chart errors were for patients who shared the correct patient's last name. In $59 \% \pm 9 \%$ of the interceptions, the clinician had both patient charts open when initiating the first order. Both patients were under the care of the clinician in all but one instance $(97 \% \pm 3 \%)$.

The interception rate did not vary as a function of venue or the type of clinician who triggered the alert, but did show significant variation by the type of medication ordered: metformin and metoprolol $0.81 / 1000$ alerts versus others $0.17 / 1000$ alerts $(\mathrm{p}<0.001)$ (table 3$)$. Interestingly, only 15 medications were involved in the 32 errors, the most common being metoprolol and metformin.

\section{DISCUSSION}

As with any complicated process, medical errors are more likely the result of poor systems and procedures than just mistakes by 
Table 2 Description of all intercepted wrong-patient medication errors

\begin{tabular}{|c|c|c|c|c|c|}
\hline Medication & Recipient & Location & $\begin{array}{l}2 \text { Charts } \\
\text { open at } \\
\text { same } \\
\text { time?* }\end{array}$ & $\begin{array}{l}\text { Caring } \\
\text { for both } \\
\text { patients }\end{array}$ & $\begin{array}{l}\text { Delay } \\
\text { (min) } \dagger\end{array}$ \\
\hline Albuterol & Housestaff & Inpatient & Yes & Yes & 1 \\
\hline Alendronate & Housestaff & Inpatient & Yes & Yes & 0 \\
\hline Amlodipine-valsartan & Attending & Ambulatory & Yes & Yes & 1 \\
\hline Diltiazem & Housestaff & ED & Yes & Yes & 0 \\
\hline Fluticasone & Housestaff & Ambulatory & No & Yes & 9 \\
\hline Glipizide & Nurse & Ambulatory & No & Yes & $335 \ddagger$ \\
\hline Glipizide & Housestaff & Inpatient & Yes & Yes & 3 \\
\hline Glyburide & Housestaff & Ambulatory & No & Yes & 2 \\
\hline Glyburide & Attending & Ambulatory & Yes & Yes & 1 \\
\hline $\mathrm{HCTZ}$ & Attending & Ambulatory & Yes & Yes & 1 \\
\hline $\mathrm{HCTZ}$ & Attending & Ambulatory & Yes & Yes & 1 \\
\hline $\mathrm{HCTZ}$ & Housestaff & ED & Yes & Yes & 5 \\
\hline Insulin regular & Housestaff & ED & Yes & Yes & 0 \\
\hline Labetalol & Housestaff & ED & No & Yes & 0 \\
\hline Labetalol & Housestaff & Inpatient & Yes & Yes & 2 \\
\hline Lisinopril & Housestaff & Inpatient & Yes & Yes & 0 \\
\hline Metformin & Housestaff & Ambulatory & Yes & Yes & 10 \\
\hline Metformin & Nurse & ED & No & No & 5 \\
\hline Metformin & Housestaff & Inpatient & No & Yes & 10 \\
\hline Metformin & Housestaff & Inpatient & Yes & Yes & 0 \\
\hline Metformin & Housestaff & Inpatient & Yes & Yes & 0 \\
\hline Metformin & Housestaff & Inpatient & Yes & Yes & 1 \\
\hline Metoprolol & Attending & Ambulatory & No & Yes & 1 \\
\hline Metoprolol & Housestaff & ED & Yes & Yes & 3 \\
\hline Metoprolol & Housestaff & Inpatient & No & Yes & 1 \\
\hline Metoprolol & Housestaff & Inpatient & No & Yes & 0 \\
\hline Metoprolol & Housestaff & Inpatient & No & Yes & 0 \\
\hline Metoprolol & Attending & Inpatient & No & Yes & 0 \\
\hline Metoprolol & Housestaff & Inpatient & Yes & Yes & 3 \\
\hline Nifedipine & Housestaff & Inpatient & No & Yes & 0 \\
\hline Simvastatin & Housestaff & Ambulatory & Yes & Yes & 5 \\
\hline Verapamil & Housestaff & Ambulatory & No & Yes & 1 \\
\hline \multicolumn{6}{|c|}{$\begin{array}{l}\text { * In the Cerner Powerchart, more than } 1 \text { chart can be open at the same time as a site } \\
\text { specific preference. } \\
\text { †The events were only captured to the minute and reported to the minute. } \\
\text { †The error was intercepted based on a verbal order, the attending clinician was } \\
\text { notified, and the second order was placed } 355 \text { min later. However, review of the } \\
\text { chart identified that the decision to replace the order in the correct patient chart was } \\
\text { rapid. }\end{array}$} \\
\hline
\end{tabular}

individuals. ${ }^{20}$ EMR and CPOE systems have created new problems that often are not anticipated or recognized. Many of these are related to poor user-interface design and poor workflow. $^{6-9} 1121$ One way to improve system quality is through redundant error checking. We have demonstrated one mechanism of error checking by leveraging medication indications with the problem list. The idea of reconciling medication indications with the problem list is not new, and is based on the concept of medication-problem list mismatches. ${ }^{22} 23$

CDS systems associated with CPOE typically have attempted to use drug-drug interactions, or more recently drug-laboratory interactions, to reduce medication errors. The drug-problem list alerts described here attempt to exploit the relationship between medications and problems (ie, diagnoses, indications). These alerts have been shown to improve problem list documentation. ${ }^{14}{ }^{15}$ Although problem list documentation always has been
Table 3 Wrong-patient alerts by venue, clinician type, and medication

\begin{tabular}{|c|c|c|c|}
\hline Venue & $\begin{array}{l}\text { Intercepted } \\
\text { errors }\end{array}$ & Alerts & $\begin{array}{l}\text { Rate } \\
\text { (interceptions/1000 alerts) }\end{array}$ \\
\hline $\begin{array}{l}\text { Emergency } \\
\text { department }\end{array}$ & 6 & 17668 & $0.34 \pm 0.14^{\mathrm{NS}}+$ \\
\hline Inpatient & 15 & 53787 & $0.28 \pm 0.07$ \\
\hline Ambulatory & 11 & 48196 & $0.23 \pm 0.07$ \\
\hline \multicolumn{4}{|c|}{ Ordering clinician } \\
\hline Housestaff & 24 & 98298 & $0.24 \pm 0.05^{\mathrm{NS}}$ \\
\hline Attending & 6 & 22453 & $0.27 \pm 0.11$ \\
\hline Other & 2 & 6569 & $0.30 \pm 0.22$ \\
\hline \multicolumn{4}{|l|}{ Medication } \\
\hline $\begin{array}{l}\text { Metformin and } \\
\text { metoprolol }\end{array}$ & 13 & 16084 & $0.81 \pm 0.22 *$ \\
\hline Others & 19 & 111236 & $0.17 \pm 0.04$ \\
\hline Total & 32 & 127320 & $0.25 \pm 0.04$ \\
\hline \multicolumn{4}{|c|}{$\begin{array}{l}\text { The results of comparisons among the values in this section were not statistically } \\
\text { significant. } \\
{ }^{*} p<0.001 \text { using the } \chi^{2} \text { statistic. } \\
\text { tThe error reported is the SE of a proportion. }\end{array}$} \\
\hline
\end{tabular}

thought of as a means to improve patient care, ${ }^{24}$ and is required by both the Joint Commission ${ }^{25}$ and meaningful use, ${ }^{1}$ our study demonstrated that drug-problem list alerts have an additional, beneficial effect: they help to intercept wrong-patient medication errors. Safeguards against wrong-patient errors can be implemented at multiple points in the medication ordering sequence, detecting and correcting problems before, during, and after data entry. The indication alerts we studied function during data entry, and can be implemented independently or in combination with other safeguards.

One potential pre-order safeguard against wrong-patient medication errors is to limit the number of charts that a clinician can have open at one time. In our analysis, $60 \%$ of the intercepted errors were associated with at least two open charts. However, the chart selection process itself may facilitate wrong patient selection through pick list or other menu selection errors. ${ }^{11}$ Without direct study, and ignoring the efficiency benefits of each feature, it is not clear which system promotes more errors, allowing multiple open charts or allowing only one chart but requiring more frequent chart selections. This topic requires more study.

Recently, Adelman et al examined two approaches to help clinicians decrease intercepted wrong-patient medication errors. One was for prescribers to make a single-click confirmation that they had verified patient identity before entering an electronic order. This reduced self-intercepted wrong-patient errors by $16 \%$. The other was to have clinicians re-key a patient's initials, gender, and age before entering an electronic order, which reduced self-intercepted wrong-patient errors by $41 \%$. Self-intercepted wrong-patient errors were measured using a 'retract-and-reorder' logic which looked for all instances where a single provider canceled an order and placed an order for the same medication in another chart within $10 \mathrm{~min}$ of signing the initial order. This method was shown to have a positive predictive value of $76 \% .^{13}$

Another technique recently published by Hyman et $a l^{26}$ showed a $40 \%$ reduction in wrong-patient errors when a picture of the patient was displayed at the time of final order. The analysis in the study was done on actual non-intercepted errors and 
showed a numerical reduction, although the errors were selfreported and the total number was small. Nonetheless, the method is promising, and is likely to be more efficient than more interruptive safeguards.

For analysis of post-order safeguards, Carpenter and Gorman evaluated an algorithm which, after patient discharge, compared patient medication prescriptions to the patient's medical record, identifying a $10 \%$ mismatch rate. ${ }^{22}$ In terms of medical impact, $52 \%$ of the mismatches were identified as being clinically relevant. Approximately two-thirds of the mismatches concerned patients whose drug treatment did not have a corresponding medical problem documented in their medical record, and one-third were patients whose prescribed drug treatment of their medical problems was not appropriate.

The relationship between medications, indications, and problem lists or billing diagnoses could be used retrospectively on its own, or as a part of a surveillance system. This relationship could help improve the specificity of a medication-laboratory alert. For instance, knowledge of the presence of atrial fibrillation in patients with congestive heart failure would allow for a more specific alert based on elevated digoxin levels, since the appropriate level of digoxin is dependent on the indication. ${ }^{27}$ In studies that examine the risk for drug name confusion (eg, Basco et $a l^{28}$ ), the connections between the medications and the problem list could help improve the specificity of the alerting system.

The present study evaluated indication-based alerts during medication ordering. We found an interception rate of 0.25 errors per 1000 alerts. This is difficult to compare directly with other studies since our alerts are a non-random subset of all medication orders. As one comparison, Adelman et al ${ }^{13}$ identified a retract and re-order rate of $0.76 / 1000$, of which 0.58 / 1000 were estimated to be wrong-patient errors. It would not be reasonable to compare our rate to that of Adelman et al, given that his relied on self-intercepted errors after submission of the order and ours was from interceptions prior to signature. Our interception rate may differ for those errors which may otherwise have been intercepted after submission. It would be very difficult to measure all wrong-patient medication errors as many do not produce harm, so careful measurement of adverse drug events would not suffice.

Because we do not know the magnitude of wrong-patient errors, is it difficult to say how robust our method is at intercepting errors, or whether these errors would have produced adverse events.

None of the individual methods that have been shown to prevent wrong-patient medication errors will be completely effective. Our method is limited to medications for which medication-problem alerts are appropriate, which is not all medications. ${ }^{15}$ The methods used by Adelman et al ${ }^{13}$ reduced self-intercepted errors by an estimated $40 \%$, but increased clinician order time by over $6 \mathrm{~s}$ per order. The absolute error reduction using photographs, as suggested by Hyman et $a l,{ }^{26}$ is uncertain and effectiveness may vary, as some patients may appear similar when ill, may appear quite different while in the intensive care unit, and neonates often appear very similar. It is likely that a combination of these methods, used more or less simultaneously or at least in an integrated fashion, will be required to achieve optimal reduction of wrong-patient medication errors.

\section{LIMITATIONS}

This study was performed at a single medical center with significant housestaff ordering. Although no differences were found in the housestaff and attending clinician rates, the power to determine this difference was low, thus it is possible the magnitude of the benefit of the intervention might change based on the type of clinician. In addition, the intervention study only used a subset of medications for which the alerts have been built. The data suggested the possibility of variation based on medication, thus a fully developed system with more medications may have a different error interception rate.

\section{CONCLUSION}

Wrong-patient errors, intercepted or not, are known to occur in CPOE. Reduction in these errors can be pursued using a variety of recently published methods. We found that implementing CPOE alerts to help providers improve patient problem list completeness also helped clinicians notice a discordance between a medication's indications and the patient whose medical record they were using, allowing the clinician to recognize and cancel pending wrong-patient errors at a rate of 0.25 per 1000 alerts. Thus indication-based alerts yield the dual benefit of intercepting wrong-patient medication errors and improving the accuracy and completeness of problem list documentation.

Funding This project was supported in part by grant number U19HS021093 from the Agency for Healthcare Research and Quality. The content is solely the responsibility of the authors and does not necessarily represent the official views of the Agency for Healthcare Research and Quality.

\section{Competing interests None.}

Ethics approval The University of Illinois at Chicago Institutional Review Board approved this study.

Provenance and peer review Not commissioned; externally peer reviewed.

Data sharing statement This was a retrospective observational study and as such no primary data were produced and only routine clinical data, which will not be shared, were analyzed.

\section{REFERENCES}

1 Blumenthal D, Tavenner M. The 'meaningful use' regulation for electronic health records. N Engl J Med 2010;363:501-4.

2 Bates DW, Leape L, Cullen DJ, et al. Effect of computerized physician order entry and a team intervention on prevention of serious medication errors. JAMA 1998;280:1311e16.

3 Bates DW, Teich JM, Lee J, et al. The impact of computerized physician order entry on medication error prevention. J Am Med Inform Assoc 1999:6:313e21.

4 Reckmann MH, Westbrook Jl, Koh Y, et al. Does computerized provider order entry reduce prescribing errors for hospital inpatients? A systematic review. J Am Med Inform Assoc 2009;16:613e23.

5 Longhurst $\mathrm{CA}$, Parast $\mathrm{L}$, Sandborg $\mathrm{Cl}$, et al. Decrease in hospital-wide mortality rate after implementation of a commercially sold computerized physician order entry system. Pediatrics 2010;126:14-21.

6 Bates DW, Cohen $M$, Leape $L L$, et al. Reducing the frequency of errors in medicine using information technology. J Am Med Inform Assoc 2001;8:299-308.

7 Campbell EM, Sittig DF, Ash JS, et al. Types of unintended consequences related to computerized provider order entry. J Am Med Inform Assoc 2006;13:547e55.

8 Koppel R, Metlay J, Cohen A, et al. Role of computerized physician order entry systems in facilitating medication errors. JAMA 2005;293:1197-203.

9 Ash J, Sittig D, Poon E, et al. The extent and importance of unintended consequences related to computerized provider order entry. J Am Med Inform Assoc 2007; 14:415-23

10 Ash JS, Gorman PN, Hersh WR, et al. Perceptions of house officers who use physician order entry. Proc AMIA Symp 1999;471-5.

11 Koppel R, Metlay JP, Cohen A, et al. Role of computerized physician order entry systems in facilitating medication errors. JAMA 2005;293:1197-203.

12 Wilcox $\mathrm{A}$, Chen $\mathrm{Y}-\mathrm{H}$. Hripcsak minimizing electronic health record patient-note mismatches. J Am Med Inform Assoc 2011;18:511-14.

13 Adelman JS, Kalkut GE, Schechter CB, et al. Understanding and preventing wrong-patient electronic orders: a randomized controlled trial. J Am Med Inform Assoc Published Online First: 29 June 2012 doi:10.1136/amiajnl-2012-001055

14 Galanter WL, Hier DB, Jao C, et al. Computerized physician order entry of medications and clinical decision support can improve problem list documentation compliance. Int J Med Inform 2010;79:332-8. 
15 Walton SM, Galanter WL, Rosencranz H, et al. A trial of inpatient indication based prescribing during computerized order entry with medications used off-label. Appl Clin Inf 2011:2:94-103.

16 ICD-9-CM, International Classification of Diseases, ninth revision, Clinical Modification, http://www.cdc.gov/nchs/about/otheract/icd9/abticd9.htm (accessed 3 Dec 2012)

17 SNOMED, Systematized Nomenclature of Medicine, http://www.cap.org/apps/cap. portal?nfpb=true\& pagelabel=snomed page (accessed 3 Dec 2012)

18 Raschke R, Gollihare B, Wunderlich T, et al. A computer alert system to prevent injury from adverse drug events. JAMA 280. 1998;15:317-1320.

19 Galanter WL, Didomenico R, Polikaitis A. A trial of automated decision support alerts for contraindicated medications using computerized physician order entry. J Am Med Inform Assoc 2005;12:269-74.

20 Committee on Quality of Health Care in America. To Err is human: building a safer health ystem. Washington DC, USA: Institute of Medicine, 2000.

21 Committee on Patient Safety and Health Information Technology. Health IT and patient safety: building safer systems for better care. Washington DC, USA: Institute of Medicine, 2012.
22 Carpenter J, Gorman P. Using Medication List-Problem List Mismatches as Markers of Potential Error AMIA. Annual Symposium Proceedings, 2002.

23 Jao C, Hier D, Galanter W. Using clinical decision support to maintain medication and problem lists: a pilot study to yield higher patient safety. Syst Man Cybern 2008:739-43.

24 Weed LL. Medical records that guide and teach. N Eng J Med 1968;278:593-600.

25 Comprehensive Accreditation Manual for Hospitals. The joint commission on accreditation of healthcare organizations. IL: Oakbrook Terrace, 1996.

26 Hyman $\mathrm{D}$, Laire $\mathrm{M}$, Redmond $\mathrm{D}$, et al. The use of patient pictures and verification screens to reduce computerized provider order entry errors. Pediatrics 2012;130: e211-19.

27 Bauman JL, Didomenico RJ, Galanter WL. Mechanisms, manifestations, and management of digoxin toxicity in the modern era. Am J Cardiovasc Drugs 2006;6:77-86.

28 Basco WT Jr, Ebeling M, Hulsey TC, et al. Using pharmacy data to screen for look-alike, sound-alike substitution errors in pediatric prescriptions. Acad Pediatr 2010;10:233-7. 